\title{
LA COMUNICOLOGÍA: VIEJOS COMPROMISOS, CIENCIA TRADICIONAL Y PERSPECTIVA CRÍTICA
}

\author{
COMMUNICOLOGY: OLD COMMITMENTS, TRADITIONAL SCIENCE \\ AND CRITICAL PERSPECTIVE
}

\author{
Rainer Rubira García \\ Belén Puebla Martínez \\ Elena Carrillo Pascual \\ Universidad Rey Juan Carlos, Madrid. España/Spain \\ rainer.rubira@urjc.es \\ belen.puebla@urjc.es \\ e.carrillo.pascual@gmail.com
}

Recibido/Received: 12/05/2013

Aceptado/Accepted: 09/09/2013

\section{RESUMEN}

Este texto aborda, desde un punto de vista crítico e histórico, los procesos de configuración del campo académico de las ciencias de la comunicación, teniendo en cuenta las particularidades del contexto en que la disciplina emergió. A partir del estudio de diferentes perspectivas epistemológicas contrapuestas al interior de la Comunicación, como área de investigación aún en proceso de articulación, se defiende la necesidad de fortalecer un enfoque crítico en la praxis científica de los agentes reproductores del campo. La relevancia de entender los intercambios comunicativos en su dimensión social y humanística, desde una visión crítica, así como el valor transformador de estos, como forma de contribuir al enriquecimiento de los individuos y de la sociedad a la que pertenecen, constituye uno de los elementos principales de discusión en este artículo.

\section{PALABRAS CLAVE}

Comunicación, paradigma, teoría, informacionalismo.

\section{SUMARIO}

1. El nacimiento de las ciencias de la comunicación: requerimientos históricos. 2. El poder del capital dicta los rumbos epistemológicos. 3. La irrupción crítica y la crisis de la comunicología. 4. La realidad es también el modo en que nos preguntamos acerca de ella: la matematización de la comunicación; 5. Particularidades de la propuesta de Shannon y Weaver. 6. Persistencia del informacionalismo, necesidad de la perspectiva crítica. Bibliografía.

\footnotetext{
ABSTRACT

This text deals, from a critical and historical perspective, with the shaping processes of the communication sciences academic field, taking into account the particularities of the context in which the discipline emerged. From the study of different opposing epistemological perspectives within Communication, as a research area still in the process of articulation, the need to strengthen a critical approach in the scientific praxis of the agents in charge of reproducing the field is encouraged. The significance to understand communicative interchanges in their social and humanistic dimension, from a critical point of view, as well as their transformative value, as a way of
} 
contributing to the enrichment of individuals and society to which they belong, is one of the main elements in discussion in this article.

\section{KEYWORDS}

Communication, paradigm, theory, informationalism.

\section{CONTENTS}

1. The birth of Communication Sciences: historical requirements. 2. The power of capital dictates epistemological paths. 3 . The emergence of criticism and the crisis of communications theory. 4 . The reality is also the way we asked about it: the mathematization of communication. 5. Special features of the Shannon and Weaver's proposal. 6. Persistence of informationalism. The need for a critical perspective. References.

\section{EL NACIMIENTO DE LAS CIENCIAS DE LA COMUNICACIÓN: REQUERIMIENTOS HISTÓRICOS}

Las ciencias de la comunicación -denominación harto polémica, todavía no aceptada por algunos- se constituyeron en campo autónomo de conocimiento hace, relativamente, muy poco.

Durante los años veinte del pasado siglo, en medio de un contexto social convulso, caracterizado por la ocurrencia de conflictos bélicos, crisis económicas y enfrentamientos ideológicos, los fenómenos comunicativos comenzaron a ganar la atención general.

Después de Aristóteles, quien se interesó en su momento por la comunicación como vehículo para el entendimiento humano, el estudio de los "actos expresivos" (Martín Serrano et al., 1982) quedó sumergido largo tiempo, aunque con esporádicas apariciones, siempre a la sombra de análisis puntuales practicados desde la estética, la oratoria o la literatura.

Esta situación cambió con la llegada del siglo XX, ante la emergencia de la sociedad de masas, el protagonismo cada vez más palpable de la tecnología y la entrada del capitalismo en su fase imperialista de desarrollo.

La comunicación se vuelve en las primeras décadas de la centuria un recurso estratégico de control social, se transforma con rapidez en un mecanismo de gestión de la esfera pública.

Entonces el mundo ya no era el mismo. De hecho, venía cambiando desde finales del siglo XIX. Las ciudades crecían de modo acelerado y se avizoraba una explosión demográfica de gigantescas proporciones. La industria se ubicaba sin discusión en el centro de la actividad económica de los países más avanzados. La migración desde los espacios rurales a los urbanos de miles de individuos que se asentaban en arrabales ponía en tensión la estructura social imperante.

Refiriéndose a este proceso, Ortega y Gasset (1958:35) diría: "Hay un hecho que, para bien o para mal, es el más importante en la vida europea de la hora presente. Este hecho es el advenimiento de las masas al pleno poderío social. (...) Se llama la rebelión de las masas".

El liberalismo, que había triunfado como filosofía política y económica, tenía ante sí el reto de controlar la nueva situación creada por el crecimiento de los monopolios. El proyecto hegemónico burgués debía ser capaz de involucrar a las masas, de conectarlas sin que ello implicara una socialización excesivamente peligrosa. Para ello, el capital convocó a dos de sus aliados esenciales: la ciencia y la tecnología, con el fin de estandarizar y maximizar la influencia de la comunicación pública. 
De tal suerte, muy pronto la imprenta se perfeccionó, el cine adquirió carácter industrial y comenzó la comercialización de la radio. En 1885 se moderniza la imprenta gracias a la invención de la linotipia por Ottmar Mergenthaler. Luego se introducen mejoras sustanciales con la tecnología off-set. Por su parte, Hollywood comienza a organizarse entre 1909 y 1913. En 1910, se lanza al mercado la primera representante del star-system: Mary Pickford. Las primeras transmisiones regulares de radio con motivos de entretenimiento se realizaron en 1920 por la Sociedad Radio Argentina en Buenos Aires; pero la emisora pionera de contenido informativo fue la KDKA de EE.UU., que inició sus labores ese mismo año (Williams, 1992). De forma paralela, los científicos sociales se vieron precisados a contestar las preguntas de anunciantes y políticos acerca del impacto de los medios sobre los sujetos, problemática que detonó el origen del campo de investigación de la comunicología.

La investigación mediática sería priorizada por encima de la comprensión de los intercambios comunicativos a nivel interpersonal. La comunicología se articularía con preferencia alrededor de la comunicación tecnologizada, o sea, de la comunicación de masas.

En esta etapa predomina la idea de comunicación como sinónimo de persuasión, es decir, como propaganda, publicidad o relaciones públicas.

Asimismo, el periodismo, de la mano de Hearst, el famoso magnate retratado por Orson Welles en la película Citizen Kane, entra a formar parte de esta tríada para el tratamiento y manipulación del concepto acuñado por Walter Lippman (1922) a la sazón: la opinión pública. Este concepto originó una fértil línea de investigación sociológica y comunicológica que llega hasta nuestros días. Las encuestas de opinión nacieron en EEUU en los años treinta impulsadas por George Gallup, quien comenzó a realizar sondeos de opinión pública y de mercado con el apoyo tanto de entidades gubernamentales como de empresas del sector privado.

Sobre la significación del periodismo para la sociedad de masas reflexionaría Weber en un discurso pronunciado en 1910: "la prensa ha provocado cambios extraordinarios en las costumbres de lectura, así como en el carácter y en la manera en que el hombre moderno percibe el mundo externo" (Wolf, 1994:49).

En el período entreguerras estas cuatro disciplinas, bajo el influjo decisivo de los Estados Unidos y de Alemania, van a convertirse en el eje cristalizador para la conformación de las ciencias de la comunicación.

La manera en que sobre todo la propaganda acompañó el ascenso de los regímenes totalitarios en Europa, en especial, en Italia y Alemania, y el uso magistral de las relaciones públicas por parte de las instituciones gubernamentales y privadas en EE.UU. colocó en posición privilegiada a la comunicación persuasiva para ser financiada y pensada.

\section{EL PODER DEL CAPITAL DICTA LOS RUMBOS EPISTEMOLÓGICOS}

Comúnmente se citan dos obras fundamentales para ilustrar la tónica transmisiva y positivista, asumida por los primeros autores de la comunicología: Propaganda Techniques in the World War, de 1927, escrita por Harold D. Lasswell y Public Opinion, de Lippman, concebida en 1922.

Además, se menciona Le Viol des Foules par la Propaganda Politique, de Serge Tchakhotine, editada en 1939 en París por Gallimard. 
Sin embargo, a menudo se ignoran los aportes de Goebbels al campo de la comunicación, presentados en la prensa alemana de la época y en papeles personales.

En el Völkischer Beobachter del 8 de septiembre de 1934 afirmaba Goebbels que "sólo la radio había podido realizar plenamente el efecto de choque de la palabra revelándose como el instrumento más potente para guiar a las gentes. (...) Era sobre todo necesario lograr encontrar un equilibrio favorable (y difícil) entre los componentes de la Haltung (el comportamiento susceptible de observación) y de la Stimmung (el estado de ánimo)" (Wolf, 1994:35). Llama la atención la relevancia otorgada al comportamiento observable y su vinculación con los sentimientos de los sujetos como medida para corroborar los efectos mediáticos.

Fue en los Estados Unidos, el país que pondría a tono el modelo fordista de desarrollo, el país que saldría como potencia económica absoluta de la debacle causada por la Primera Guerra Mundial, donde se dieron las condiciones para iniciar el estudio de la comunicación de masas.

En 1933 se publican en dicha nación 12 volúmenes sobre los efectos de los medios en la era contemporánea bajo el auspicio de la Fundación Payne, tras una intensa investigación encabezada por un equipo de científicos sociales de variada procedencia: psicólogos, sociólogos, pedagogos, politólogos, entre otros. Se considera éste el momento de fundación de la comunicación en tanto ciencia.

Desde el punto de vista metodológico el nuevo campo se nutrió de instrumentos tales como las escalas de actitudes, mediciones fisiológicas, técnicas experimentales, cuestionarios, entrevistas, relatos personales, análisis de contenido, etc., en su mayoría elaborados por la psicología y la sociología más tradicionales.

En el orden teórico, predominó la importación de concepciones provenientes de la psicología de masas y el conductismo.

El cálculo de la eficiencia mediática era fundamental para satisfacer las demandas de conocimientos de los agentes económicos y políticos. Por tanto, debía predominar el trabajo empírico por encima de la teorización. Se exigían resultados concretos para determinar dónde invertir el dinero, en qué tipo de anuncio, sobre cuáles públicos, en qué medios.

Las ciencias sociales -y la comunicación intentaba sumarse al grupo de éstas- debían mostrar su valor predictivo, su utilidad para el capital, tanto como las ciencias naturales, lo cual no era tarea sencilla. En relación con lo anterior, Max Horkheimer aclara en su texto de 1937, Teoría tradicional y teoría crítica: “(...) las denominadas ciencias del espíritu tienen, por lo demás, un fluctuante valor de mercado, deben limitarse a competir modestamente con las ciencias naturales, más afortunadas, cuya posibilidad de aplicación está fuera de duda." (Horkheimer, 1974:225-226).

No es casual que la cuantificación estadística estricta sea la meta fundamental de la investigación comunicológica desde sus primeros años. Para ganar la competencia que señala Horkheimer, la comunicación tenía que operar con los mismos parámetros que la física, la matemática o la química, de ahí la filiación con la perspectiva positivista y la matematización ejecutada por Shannon y Weaver (1949).

Resulta interesante el modo en que se apartaron y desecharon análisis muy serios como los encabezados por la Escuela de Chicago por no cumplir los requerimientos del mercado. Goffman (1959) -fundador de la microsociología-, Watzlawick (1967), entre otros miembros de esta escuela, realizaron estudios de comunicación más centrados en lo cotidiano y lo interpersonal que no entraron en el "mainstream" comunicológico al no satisfacer las preguntas del capital, que exigía respuestas utilizables y expeditas. 
La corriente de efectos fue ganando en complejidad, sobre todo a partir de los diseños metodológicos de Blumer $(1956 ; 1969)$. Se pasó de considerar los efectos de la comunicación de masas como inmediatos y absolutos a valorar la incidencia de los grupos y las variables demográficas en la recepción de los mensajes. Aquí se produce una bifurcación entre una tendencia de análisis psicológico y otra más sociológica.

La Escuela de Yale, liderada por Carl Hovland (1948); -quien desarrolló la mayor parte de su trabajo para la Information and Education Division del ejército norteamericano-, se concentró en las barreras psicológicas del consumo mediático; Paul Lazarsfeld (1948), por su lado, en muchas ocasiones a solicitud de entidades como la Rockefeller Foundation, favoreció los estudios de raíz sociológica sobre la conformación de los estados de opinión y los mecanismos de propagación de los contenidos de la comunicación.

Ambos autores, de modo simultáneo, trazaron caminos diferentes en la investigación mediológica, pero mantuvieron siempre el mismo interés por lo observable y lo cuantificable.

El estrecho contacto de Hovland y Lazarsfeld con las estructuras de poder, la incidencia de éstas en la formulación de los objetos de estudio y, por ende, en los propios resultados esperados, hizo que este último incluso calificara la investigación comunicológica norteamericana con el término de administrativa. Como bien apunta Horkheimer (1974: 261) "Todas las teorías que surgen deben ser adjudicadas a las tomas de posición prácticas, a las clases sociales que tienen relación con ellas".

\section{LA IRRUPCIÓN CRÍTICA Y LA CRISIS DE LA COMUNICOLOGÍA}

Mientras esto ocurría en Estados Unidos, en Alemania Max Horkheimer se convertía en el director del Institut für Sozialforschung de Frankfurt, organizado para pensar y actuar sobre la sociedad desde una mirada crítica. A partir de presupuestos epistemológicos tomados del marxismo y del primer Freud en lo fundamental, un conjunto de intelectuales como Theodor Adorno, Walter Benjamin y Erich Fromm fueron incorporándose junto con Horkheimer a la labor del Instituto.

Tras 10 años de actividad continua, en 1933 las fuerzas hitlerianas cierran el proyecto, debido al origen judío y a la filiación marxista de sus principales integrantes. Después de un tiempo de angustia, Horkheimer recibe el apoyo de su amigo Paul Lazarsfeld -entonces nombrado director de la Office of Radio Research en la Universidad de Princeton- para establecerse en la Universidad de Columbia.

El maltrecho equipo de Frankfurt se reúne ahora en Nueva York con la ausencia de Benjamin, quien se suicidó en la frontera franco-española ante el peligro de ser atrapado por los nazis.

En 1940, Lazarsfeld se desplaza a Columbia y abre el Bureau of Applied Social Research con la cual comienza una muy interesante convivencia entre dos maneras totalmente distintas de hacer ciencia. De una parte, Horkheimer con su impronta crítica desmontando la cultura de masas, las industrias culturales, el "Enlightenment"; de la otra, Lazarsfeld con el método positivista.

A pesar de que se dieron algunas colaboraciones -Adorno, por ejemplo, trabajó para Lazarsfeld como especialista de música- los estudios llevados a cabo por los dos equipos, incluso sobre los mismos temas, eran a todas luces incompatibles.

En más de una ocasión Lazarsfeld solicitó a su par alemán resultados prácticos para mostrar a los patrocinadores pero encontró siempre una estoica negativa. El espíritu de 
Frankfurt generaba textos inquietantes, peor aún, textos inútiles a los ojos de las corporaciones.

Un párrafo como el que sigue no podía ser del agrado ni de los magnates de las industrias culturales, ni de los científicos sociales que servían a estos: "Las distinciones enfáticas, como aquellas entre films de tipo a y b o entre las historias de semanarios de distinto precio, no están fundadas en la realidad, sino que sirven más bien para clasificar y organizar a los consumidores, para adueñarse de ellos sin desperdicio. Para todos hay algo previsto, a fin de que nadie pueda escapar; las diferencias son acuñadas y difundidas artificialmente. El hecho de ofrecer al público una jerarquía de cualidades en serie sirve sólo para la cuantificación más completa. Cada uno debe comportarse, por así decirlo, espontáneamente, de acuerdo con su level determinado en forma anticipada por índices estadísticos, y dirigirse a la categoría de productos de masa que ha sido preparada para su tipo. Reducidos a material estadístico, los consumidores son distribuidos en el mapa geográfico de las oficinas administrativas (que no se distinguen prácticamente más de las de propaganda) en grupos según los ingresos, en campos rosados, verdes y azules" (Horkheimer y Adorno, 1987).

Los contrastes manifiestos entre la Teoría Crítica y la Investigación Administrativa, compartiendo el tiempo, el espacio y hasta los mismos objetos de estudio generaron una crisis cismática para la comunicación en tanto ciencia, crisis que todavía hoy provoca posiciones encontradas en la reproducción del campo. La incapacidad de la comunicología para dialogar consigo misma ha sido, sin dudas, uno de los factores que más ha obstaculizado su desarrollo y consolidación.

Si bien la conjunción entre el filón psicológico y el sociológico de la investigación de la comunicación de masas nunca fue del todo completada, a nivel epistemológico se compartían principios comunes, pero entre el método crítico y el tradicional positivista manejado por la perspectiva administrativa el antagonismo se mostraba irreconciliable. Este antagonismo es explicado extensamente por Horkheimer en su ensayo Teoría tradicional y teoría crítica.

Merton, discípulo de Lazarsfeld describía la situación del siguiente modo: la corriente crítica "trata de problemas importantes de una manera empíricamente discutible, la investigación administrativa (de origen americano) trata de argumentos a menudo más triviales, pero de manera empíricamente correcta" (Merton, 1949:804).

Las ciencias de la comunicación han evolucionado arrastrando la lucha entre la perspectiva positivista y crítica, una lucha que no pocas veces se ha tornado ideológica. Los requerimientos históricos del capital han sido tan fuertes que el paradigma tradicional administrativo -paradigma dominante- llegó incluso a proponer a fines de los años cuarenta el estudio matemático de los procesos comunicativos, concebido por Shannon y Weaver (1949).

Esta visión de la comunicación como transmisión de información ha marcado el campo de manera indeleble favoreciendo más el "saber hacer" que el "saber comprender", o sea, el instrumentalismo por encima de la reflexión y la interpretación.

\section{LA REALIDAD ES TAMBIÉN EL MODO EN QUE NOS PREGUNTAMOS ACERCA DE ELLA: LA MATEMATIZACIÓN DE LA COMUNICACIÓN}

La investigación comunicológica se vio influida, desde sus inicios, por la presencia ineludible de los monopolios. El capital descubrió las posibilidades de la comunicación pública para orientar a las masas populares, lo cual significaba una increíble capacidad para gestionar mercados, catedrales de la era contemporánea. 
Los centros de poder occidentales desarrollaron el uso de la comunicación como herramienta de ingeniería social. En particular, el pujante pragmatismo americano, apoyado por una avanzada industria tecnológica, fue de los máximos responsables en la concepción del papel que debían interpretar los mass media sobre la escena social, entendidos como mecanismos de negociación y consenso de la hegemonía burguesa.

Tal vez lo anterior explique por qué los primeros estudios sobre comunicación tuvieron lugar en Estados Unidos y por qué el tema principal de investigación giró alrededor de los efectos o las consecuencias de la actividad mediática para las masas. Se imponía conocer hasta qué punto los medios eran capaces de propagar con eficiencia valores e ideas, de generar determinados estados de opinión pública.

La corriente inicial de análisis en comunicación tuvo su corolario en un modelo -la teoría matemática de la comunicación- que intentaba describir la "realidad objetiva" de los fenómenos comunicativos partiendo de un supuesto con valor de axioma: es imposible que, superando todos los obstáculos, sean físicos, psicológicos o sociológicos, un mensaje no tenga consecuencias inmediatas para quien lo recibe.

Casi todos los conceptos manejados por la teoría matemática de la comunicación parten de la cibernética, en un contexto caracterizado por las presiones de la industria militar estadounidense. La necesidad de lograr cifrados cada vez más perfectos para los intercambios de mensajes ante el advenimiento de la Guerra Fría dio preponderancia al estudio de los procesos de codificación. El poder requería de la "intelligentsia" una investigación de la comunicación de corte positivista que se enfocara en la eficiencia de la transmisión informativa. De ahí la intención de matematizar la comunicación para su análisis.

"Así pues, lo que el científico, en los más diversos campos, considera la esencia de la teoría, es propio en realidad de su tarea inmediata" (Horkheimer, 1974:228).

Nos hacemos preguntas en función de un contexto determinado y mientras configuramos las interrogantes modelamos también los fenómenos por los cuales indagamos. Esto se muestra claramente en el caso de la teoría matemática de la comunicación o teoría informacional, como también se le conoce, que ve a la comunicación como un intercambio de datos previsible y cuantificable, tal y como se lo habían propuesto los investigadores.

\section{PARTICULARIDADES DE LA PROPUESTA DE SHANNON Y WEAVER}

En 1948 ya estaban definidos cuatro de los principales pilares mediáticos, a saber, prensa, radio, cine y televisión, que comenzaba a dar sus primeros pasos. En la década de 1940 los medios masivos en los Estados Unidos estaban bastante extendidos: 1878 rotativos, 56 millones de receptores de radio, cuatro cadenas de televisión asociadas a las networks y prácticamente una sala de cine en cada barrio (Williams, 1992).

Al mismo tiempo se gestaban los gérmenes de lo que sería el quinto elemento, el formato digital.

Ese año, el matemático e ingeniero Claude Elwood Shannon escribe en el Bell System Technical Journal un trabajo titulado "A Mathematical Theory of Communication", interesado principalmente en describir la interacción entre las grandes computadoras en franco desarrollo.

Más tarde, en 1949, la Universidad de Illinois publica una monografía sobre The Mathematical Theory of Communication, firmada por el propio Shannon y comentada por 
el sociólogo Warren Weaver. Ahora, ambos autores generalizaban los planteamientos iniciales concebidos para el análisis de intercambios entre organismos artificiales con el objetivo de abarcar todos los tipos de interrelaciones comunicativas, incluidas las practicadas entre seres humanos.

La teoría de la información recibió significativos aportes de Norbert Wiener (1954), profesor de Shannon y más tarde colega suyo en el Massachusetts Institute of Technology (MIT). Wiener no sólo definió los términos cibernética y sociedad de la información; hizo además interesantes aportes alrededor de la entropía como medida del grado de desorden de un sistema.

Shannon y Weaver proponen un modelo general de comunicación, entendida como el conjunto de procedimientos por los cuales un ente afecta a otro.

Se asume, pues, una concepción transmisiva del proceso comunicativo: una fuente emite un mensaje codificado el cual se envía, mediante un canal, a un receptor que lo descodifica. El modelo de Shannon y Weaver tiene sus antecedentes más remotos en el trabajo sobre los reflejos condicionados del científico ruso Iván Pávlov (1927), quien propuso el famoso mecanismo estímulo-respuesta en la biología. El estímulo es captado por un receptor, el cual transmite el mensaje a través de una vía aferente hasta el modulador, encargado de elaborar la respuesta y enviarla, vía eferente, hacia el órgano blanco o diana, que debe ejecutarla. Como puede apreciarse algunos elementos reaparecen después en la teoría informacional. De tal suerte, se puede establecer cierto paralelismo entre el modelo matemático-informacional estadounidense y la teoría del científico ruso.

La matematización de la comunicación está en plena correspondencia con la implantación de la cibernética como filosofía social en pleno siglo XX. Siguiendo a Hobsbawn (2004:542): "Los ordenadores electrónicos, que se desarrollaron a una velocidad de vértigo después de la Segunda Guerra Mundial, especialmente tras la invención del transistor, tenían una enorme capacidad para hacer simulaciones, lo que hizo mucho más fácil que antes desarrollar (sic) modelos mecánicos de las que, hasta entonces, se consideraban las funciones básicas de los organismos, incluyendo el humano. (...) uno de los debates filosóficos habituales de la segunda mitad del siglo era si se podía, y en tal caso cómo, diferenciar la inteligencia humana de la 'inteligencia artificial'; es decir, qué es lo que había -si lo había- en la mente humana que no fuese programable en teoría en un ordenador".

Shannon concluye, sobre la base de los trabajos del lógico del XIX George Boole (en Gasser, 2000) y a partir de una sugerencia de su colega de Princeton John Tuckey, que la manera más sencilla de cifrar un mensaje es a través de dos probabilidades opuestas (si/no; on/off; 1/0).

La concepción de Shannon y Weaver sobre el bit o binary digit buscaba entender las cadenas de información como alternativas puramente cuantitativas para, de esa forma, calcular la capacidad necesaria del canal y los gastos de transmisión del mensaje.

De hecho, el objetivo central de esta teoría consistía en determinar cómo reproducir en el destinatario, de forma exacta o aproximada, un mensaje enviado por el emisor, con menos costo y en menos tiempo, esto es, con la mayor eficacia y eficiencia posible.

Optimizar la transmisión del mensaje es la divisa fuerte de la teoría matemática de la comunicación. En ese sentido, el modelo introduce el concepto de ruido para explicar la interferencia de factores externos al proceso comunicativo que perturban el mecanismo de transmisión e impiden, por tanto, la plena correspondencia entre el emisor y el receptor.

La solución propuesta al problema del ruido implica considerar la redundancia como un elemento corrector de los defectos de la cadena de comunicación. La modificación 
consciente de la estructura de códigos, según Shannon y Weaver, reduce y hasta elimina el efecto negativo del ruido. Shannon en particular observó que mientras una pequeña variación en una señal analógica distorsiona y puede concebiblemente corromper el mensaje transportado por esa señal, la naturaleza si/no, on/off de la señal digital determina que la información sea menos propensa a corromperse pues añadiendo algunos bits a la señal se puede realizar la detección y corrección automática desde el sistema.

En sí, esta teoría refleja una "realidad de comunicación dominante; es decir, reproduce una interacción comunicacional que surge a lo interno de un marco socioeconómico imperante caracterizado por la desigualdad" (Tuñón, 1995:3). Esto viene dado no sólo por la concepción transmisiva dominante en el período. Las tendencias conductistas iniciadas por Watson (1913) en la psicología favorecieron la pasividad del receptor como también el positivismo recalcó en demasía lo cuantitativo y experimental en toda la etapa inicial de la investigación en comunicación.

El modelo informacional no realiza precisión alguna sobre la significación o el contenido propiamente dicho del mensaje. La información que se transmite se analiza sólo en términos cuantitativos. Para Shannon (1949), tiene relevancia medir el tamaño de la cadena de bits, no comprender la correlación entre los códigos y su significación en la realidad.

\section{PERSISTENCIA DEL INFORMACIONALISMO, NECESIDAD DE LA PERSPECTIVA CRÍTICA}

La teoría de la información sirvió de base a la investigación de la comunicación de masas en su conjunto durante los primeros años, y aún hoy, constituye uno de los paradigmas más importantes.

Jakobson (1985), por ejemplo, toma de Shannon y Weaver algunas ideas para elaborar su teoría lingüística al descubrir varios puntos de contacto entre el lenguaje y la codificación de la información. De ahí se deriva su propuesta sobre la estructura de la lengua en forma de códigos, con significantes y significados.

Schramm (1960; 1964), por su parte, elabora desde lo informacional un modelo donde resalta la retroalimentación y el marco referencial como elementos imprescindibles para la comunicación social.

Umberto Eco (1977), en su modelo semiótico-informacional, se concentra en el aspecto semántico, en el significado de los códigos y la interpretación que los individuos hacen de ellos, pero sin abandonar la visión mecánica de la comunicación como transmisión.

La funcionalidad que demostró la teoría informacional para la corriente de los efectos contribuyó a la legitimación del modelo y significó un triunfo para los términos ruido y redundancia.

Al centrarse sobre el mensaje y su transmisión desde el punto de vista cuantitativo permitió elaborar una metodología científica con muestras y variables bien definidas, respondiendo las demandas de las industrias culturales y del capital.

La matematización de la comunicación ha sido exportada incluso a los procesos pedagógicos en la formación de comunicadores. Para cumplir con la filosofía del "saber hacer", de conocer los modos de manipular a las masas y la opinión pública, se ha entronizado en las academias una comunicología instrumentalista y positivista, enfrentada con la visión crítica que intenta, a pesar de las presiones del mercado, salvaguardar el sentido humanista del campo. 
"El futuro de la humanidad depende hoy del comportamiento crítico que, claro está, encierra en sí elementos de las teorías tradiciones y de esta cultura decadente. Una ciencia que, en una independencia imaginaria, ve la formación de la praxis, a la cual sirve y es inherente, como algo que está más allá de ella y que se satisface con la separación del pensar y el actuar, ya ha renunciado a la humanidad." (Horkheimer, 1974:270-271).

La comunicología puede constituirse verdaderamente en un espacio de saber liberador y transformador, de saber crítico, destinado a pensar y actuar sobre el futuro de los actos expresivos, a garantizar una mediación responsable y ética de la esfera pública. En ese sentido habrá que encaminar todos los esfuerzos. Sólo un cambio epistemológico de tal magnitud, inaplazable en los tiempos que corren, devolvería a las ciencias de la comunicación, hoy sumergidas en el pantano del conocimiento científico tradicional, su esencia primigenia: contribuir al desarrollo del diálogo y del entendimiento mutuo.

\section{BIBLIOGRAFÍA}

BLUMER, H. (1956), "Sociological analysis and the "variable", en American Sociological Review, Vol 21, no 6, pp. 683-690, disponible en: http://www.asanet.org/images/asa/docs/pdf/1956\%20Presiden tial\%20Address \%20(Herbert\%20Blumer).pdf, visitado 7/5/2013.

BLUMER, H. (1969), Symbolic Interactionism: Perspective and Method, Prentice Hall, Inc. Englewood Cliffs, N.J., disponible: https://campus.fsu.edu/bbcswebdav/institution/academic/social_sciences/socio logy/Reading\%20Lists/Social\%20Psych\%20Prelim\%20Readings/I.\%20Classics/1969\%20Blumer\%20$\% 20$ Symbolic\%20Interactionism.pdf, visitado $7 / 5 / 2013$.

ECO, U. (1977), Tratado de semiótica general, Lumen, Barcelona, 2000.

GASSER, J. (2000), A Boole Anthology: recent and classical studies in the logic of George Boole, Springer, Dordrecht, 2000.

GOFFMAN, E. (1959), The Presentation of Self in Everyday Life, University of Edinburgh Social Sciences Research Centre, disponible en: http://clockwatching.net/ jimmy/eng101/articles/goffman intro.pdf, visitado7/5/2013.

HOBSBAWN, E. (2004), Historia del siglo XX, La Habana, Editorial Félix Varela.

HORKHEIMER, M. (1974), "Teoría tradicional y teoría crítica", en Teoría crítica, Buenos Aires, Amorrortu.

HORKHEIMER, M. y ADORNO, T. (1987), Dialéctica del Iluminismo, Buenos Aires, Sudamericana.

HOVLAND, C. (1948), "Psychology of the communicative process", en Communications in Modern Society, pp. 59-65. Urbana, University of Illinois Press.

JACKOBSON, R. (1985), Ensayos de lingüística general, Barcelona, Planeta-Agostini.

LASSWELL, H. (1927), Propaganda Technique in the World War, Michigan, The Mit Press

LAZARSFELD, P. (1948), The People's Choice: How the Voter Makes Up His Mind in a Presidential Campaign, Columbia University Press, University of Minnesota.

LIPPMANN, W. (1922), Public Opinion, disponible en: http://www.gutenberg.org/cache/epub/6456/ pg6456.html, visitado7/5/2013.

MARTÍN SERRANO, M. et al. (1982), Teoría de la Comunicación. Epistemología y análisis de la referencia, La Habana, Editorial Pablo de la Torriente.

MERTON, R. (1949), Social Theory and Social Structure, New York, The Free Press.

ORTEGA Y GASSET, J. (1958), La rebelión de las masas, Madrid, Espasa-Calpe.

PAVLOV I. P. (1927), Conditioned Reflexes: An Investigation of the Physiological Activity of the Cerebral Cortex. London, Oxford University Press.

SCHRAMM, W. (1960), Mass communications, Urbana, IL, University of Illinois Press.

SCHRAMM, W. (1964), Mass media and national development, Stanford, CA, Stanford University Press. 
SHANNON, C. E. y WEAVER, W. (1964), The Mathematical Theory of Communication. Tenth printing, disponible: http://www.magmamater.cl/MatheComm.pdf, visitado 7/5/ 2013.

TCHAKHOTINE, S. (1939), Le Viol des Foules par la Propaganda Politique, París, Gallimard. TUÑÓN, M. (1995), Un nuevo paradigma para la comunicación, Santo Domingo, s/e.

WATSON, J. B. (1913), Psychology as the Behaviorist Views it. Psychological Review, n 20, pp. 158177, disponible en: http://psychclassics.yorku.ca/Watson/views.htm, visitado 7/5/2013.

WATZLAWICK, P.; HELMICK BEAVIN, J. y JACKSON D. (1967), Pragmatics of Human Communication. W. W. Norton\&Company, Inc. En español: Teoría de la Comunicación Humana. Interacciones, patologías y paradojas (1985) Barcelona, Herder, disponible: http://primeravocal.org/ wp-content/uploads/2011/05/Watzlawick-Paul-Teoria-De-La-Comunicacion-Humana3.pdf, visitado 10/ $5 / 2013$.

WIENER, N. (1950), The Human Use of Human Beings: Cybernetics and Society, disponible en: http://asounder.org/resources/weiner_humanuse.pdf, visitado10/5/2013.

WILLIAMS, R. (1992), Historia de la Comunicación, Barcelona, Bosch Comunicación.

WOLF, M. (1994), Los efectos sociales de los media, Barcelona, Paidós.

\section{Breve currículo:}

\section{Rainer Rubira García}

Licenciado en Comunicación Social por la Universidad de La Habana y Máster en Comunicación y Problemas Socioculturales por la Universidad Rey Juan Carlos, en Madrid. Es investigador asociado de la Fairfield University, Connecticut, Estados Unidos y profesor en la Universidad Rey Juan Carlos, Madrid, España. Ha participado en varios proyectos de investigación sobre redes sociales digitales, comunicación corporativa, estudios de Internet, género, comunicación política y comunicación internacional. Tiene publicaciones en revistas como Ecquid Novi: African Journalism Studies y el Journal of Global Media and Communication. Es miembro de la IAMCR y de ECREA. Sus intereses de investigación incluyen: teoría y metodología de investigación en comunicación, la investigación de Internet, estudios de género y comunicación, comunicación política y comunicación internacional. 


\section{Belén Puebla Martínez}

Doctora en comunicación por la Universidad Rey Juan Carlos (2013). Licenciada en Periodismo (2005) y en Comunicación audiovisual (2007) por la URJC. En 2008, obtuvo la Suficiencia investigadora (DEA) dentro del programa de doctorado Investigar y desarrollar la sociedad de la información. Es Máster de Comunicación y problemas socioculturales (2009). Desde 2009 hasta 2012 ha sido profesora visitante en la URJC. Es directora del grupo de investigación Visual. Investigando la comunicación en España, grupo multidisciplinar de jóvenes investigadores. Es co-fundadora junto a Pedro Pérez de la Revista Científica en Comunicación Aplicada Index.Comunicación de la URJC.

\section{Elena Carrillo Pascual}

Licenciada en Sociología (2006) por la Universidad Carlos III y en Publicidad y Relaciones Públicas (2009) por la URJC. Es Máster en Gestión e Investigación de la Comunicación empresarial (2010). En la actualidad está realizando su tesis doctoral sobre la representación de la realidad social en el cine. Pertenece al grupo editorial de Index.comunicación. Es miembro del grupo de investigación Visual. Investigando la comunicación en España, grupo multidisciplinar de jóvenes investigadores. 